\title{
Quantitative Morphology and Regional and Laminar Distributions of Senile Plaques in Alzheimer's Disease ${ }^{1}$
}

\author{
JOSEPH ROGERS ${ }^{\star 2}$ AND JOHN H. MORRISON‡ \\ * Department of Neurology, University of Massachusetts Medical School, Worcester, Massachusetts 01605 and $\ddagger$ Division of Preclinical \\ Neuroendocrinology and Neuroscience, Scripps Clinic and Research Foundation, La Jolla, California 92037
}

\begin{abstract}
Senile (neuritic) plaques are one of the two major neuropathologic hallmarks of Alzheimer's disease. Despite their obvious importance (e.g., they are significantly correlated with severity of dementia), there is little present information about their etiology, the specific neuronal elements that form them, or a quantitative definition of where in cortex they occur. We have sought clues to these issues by quantifying regional and laminar distributions of neocortical plaques and setting these data against the present wealth of information on neocortical cytoarchitecture and neurotransmitter-specific circuitry. Senile plaques are significantly more numerous in associative regions of neocortex than in sensory areas and are significantly more numerous in cortical laminae dominated by their role in corticocortical, associative relations. Plaques are also largest in those laminae characterized by large pyramidal cells subserving input/output functions. The quantitative distribution of senile plaques in Alzheimer's disease does not necessarily correspond to innervation patterns for any known subcortical afferent system. This, coupled with the finding that several different neurotransmitters can be immunocytochemically co-localized with plaques, casts doubts on a primary role of cholinergic deterioration in plaque etiology, and opens the possibility that neocortical senile plaques may derive from pathologic events initiated in the neocortex.
\end{abstract}

Alzheimer's disease is characterized by two classic neuropathologic hallmarks, neurofibrillary tangles and senile (or neuritic) plaques (Terry and Katzman, 1983). The latter are composed of deteriorating axons and dendrites interspersed with amyloid (Terry et al., 1964; Terry and Wisniewski, 1970), and their concentrations are correlated with severity of dementia (Blessed et al., 1968).

It is well known that plaques are not randomly distributed in brair. Cerebellum, for example, has few, if any, plaques, whereas frontal

Received January 29, 1985; Revised April 12, 1985;

Accepted April 26, 1985

\footnotetext{
'We thank Dr. Umberto De Girolami for invaluable help obtaining Alz heimer's material for study, and Stephan Scherr for expert technical assistance. The insight and encouragement of Dr. F. E. Bloom was an important factor in the research and is gratefully acknowledged. This work is supported by the Alzheimer's Disease and Related Disorders Association (J. R.) and the McArthur Foundation (J.H.M.) and the Sam and Rose Stein Trust (J. H. M.)

${ }^{2}$ To whom correspondence should be addressed, at Department of Neurology, University of Massachusetts Medical School, 55 Lake Avenue North, Worcester, MA 01605.
}

and temporal associalion cortices are thought to have many (Terry and Katzman, 1983; Kemper, 1984). With regard to subregional variations, the medial basal, lateral basal (Jamada and Mehraein, 1968: Hooper and Vogel, 1976), and central nuclei (Brockhaus, 1938) of the amygdala, and the subiculum, presubiculum, and Sommer's sector of the hippocampal formation (Jamada and Mehraein, 1968) appear to have a particular predilection for plaques. Qualitative observations from several authors have suggested that plaques are more common in superficial cortical layers (Redlich, 1898; Fischer, 1907; Fuller, 1911), although Tomlinson et al. (1968, 1970) have more recently reported an impression that plaques are more frequent in layers $\mathrm{II}$ and $\mathrm{V}$

Over the last century, great efforts have been made to define the cytoarchitecture of the neocortex with a precision extending to laminar parcellations (for recent reviews, see Braak, 1984; Feldman, 1984; Jones, 1984a, b; Kemper and Galaburda, 1984; Lund, 1984). The advent of immunocytochemistry has augmented this work by permitting visualization of specific neurotransmitter systems in the various laminae and neocortical brain regions. Against this store of knowledge, we have set out to determine with equal precision possiblc rolationships between the classical neocortical pathology of Alzheimer's disease and the organization of intrinsic and extrinsic neocortical systems, with the hope that any resulting correlations might provide important clues to the etiology of the disease. In this vein, for example, we recently showed that deteriorating somatostatin-positive fibers are constituents of probably a majority of neocortical plaques (Morrison, 1984, 1985). Similarly, immunocytochemically positive tyrosine hydroxylase, substance $P$, and choline acetyltransferase fibers have also been observed in proximity to plaques (Armstrong et al., 1984; Kitt et al., 1984). Collectively, these data suggest a multitransmitter involvement in plaque etiology and may dictate a shift in research emphasis from specific neurotransmitter systems to the intrinsic cytoarchitecture and circuitry of the cortex.

In this report, we have used cytoarchitectural principles to quantify regional and laminar distributions of plaque pathology in neocortex of Alzheimer's disease victims. We find distinct regional and laminar patterns that do not necessarily correspond to any known subcortical afferent system but, rather, are suggestive of an inherent neocortical basis for neocortical plaque formation.

\section{Materials and Methods}

Brain materials. Formalin-postfixed brains from four clinically and neuropathologically confirmed Alzheimer's disease patients were selected for study. Tissue blocks containing the entire extent (in the coronal plane) of superior frontal gyrus (Brodmann area 9) and anterior cingulate gyrus (Brodmann areas 23 and 24 ) were dissected at a level immediately rostral to the genu of the corpus callosum. Tissue blocks containing the entire coronal extent of the superior temporal gyrus were dissected at the level of the cerebral peduncles (plates 35 and 36 of the atlas of Nieuwenhuys et al., 1981). The portion quantified within this area corresponded to Heschl's gyrus (Brodmann areas 41 and 42). A final set of blocks contained striate visual 

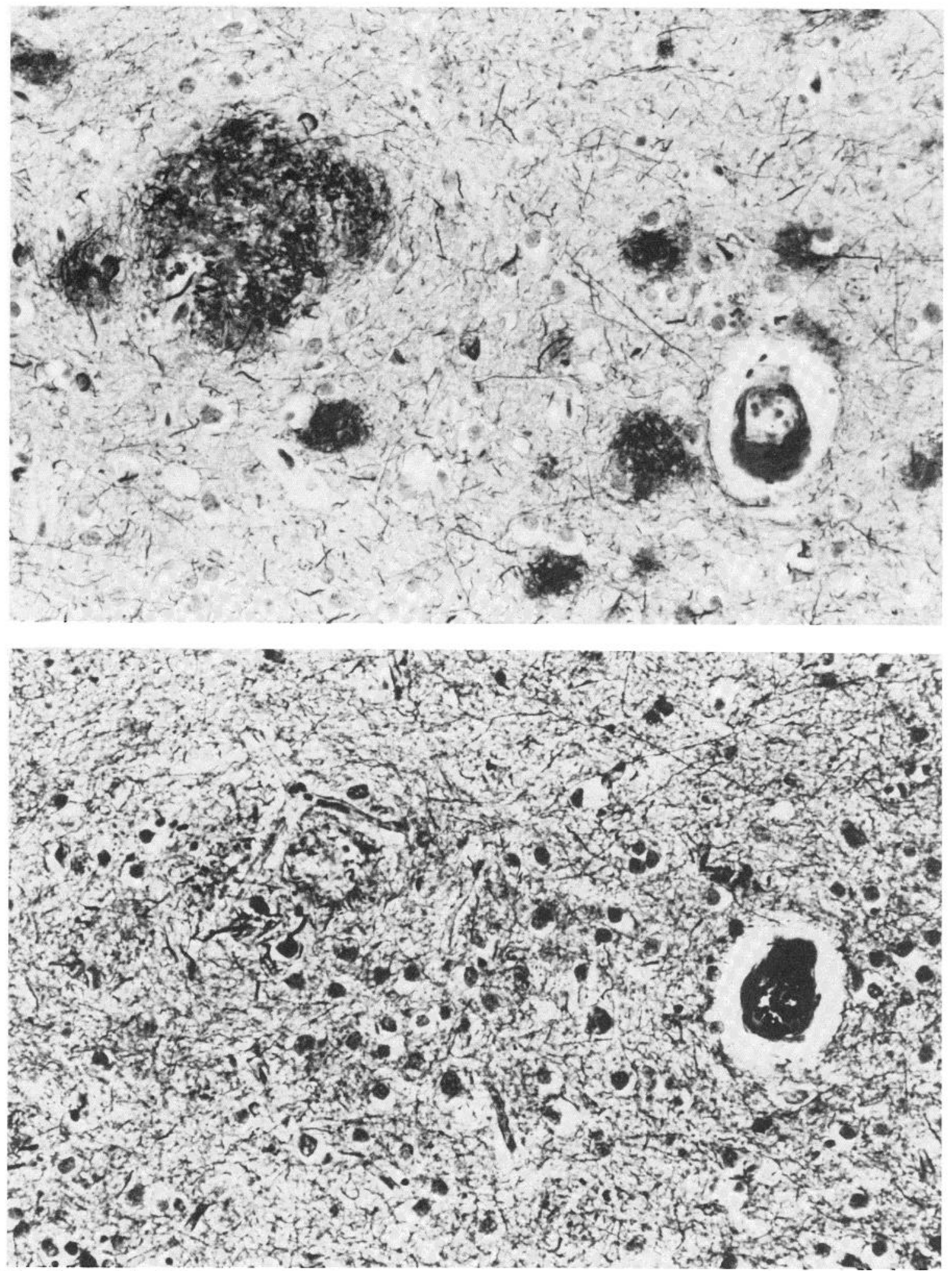

Figure 1. Top, Representative Bielschowsky staining of neuritic plaques at the border of layers I and II in superior frontal gyrus. Bottom, Similarly localized field in an immediately adjacent $6-\mu \mathrm{m}$ section using Bodian staining. Note that the Bielschowsky stain reveals amyloid deposits not seen with Bodian and, thus, gives a more complete picture of the extent of plaques.

cortex (Brodmann area 17); these were collected $3 \mathrm{~cm}$ rostral to the occipital pole within the depths of the calcarine fissure. In addition to the above landmarks, localization of the sampled cortical regions was checked by cytoarchitectonic criteria, particularly those set out by Braak (1980). For example, both the landmarks and the cytoarchitectonics (e.g., well defined and densely packed layer IV; striking columnar arrangement of layer III and $\checkmark$ pyramidal cells) defined our superior temporal gyrus sections as part of the sensory (auditory) rather than association area of that gyrus. Blocks were parafin embedded, cut at $6 \mu \mathrm{m}$, and processed for staining of senile plaques, neurofibrillary tangles, and amyloid using the method of Bielschowsky, as described by Segarra (1970). Bielschowsky staining was chosen (e.g., over Bodian staining) because it marks both neurofibrillary tangles and amyloid well, making the identification of plaques a simpler undertaking (Fig. 1). Alternate sections were stained with cresyl violet. 
Microscopy and quantification of plaques. Representative Bielschowsky and adjacent cresyl violet sections were selected for each patient case and cortical region. Photomicrographs at $\times 160$ of the superior frontal gyrus, anterior cingulate gyrus, superior temporal gyrus, and striate visual cortex were then taken, photographically enlarged, and assembled into montagcs. Montages typically encompassed an area from the pial surface through the white matter, and from the depths of the sulcus (sylvian, superior frontal, cingulate, or calcarine) to the top of the respective gyrus.

From cresyl violet montages, reference to the original sections, and reference to the cytoarchitectonic characterizations of Braak (1980), lamination patterns were determined for adjacent Bielschowsky sections. Cresyl violet laminar parcellations were marked on a plastic overlay and then transferred to Bielschowsky montages. To determine the measured area within each lamina and the area of plaques therein, a grid transparency was placed over Bielschowsky montages. Each unit in the grid measured 400 $\mu \mathrm{m}^{2}(20 \mu \mathrm{m} \times 20 \mu \mathrm{m})$ relative to the final magnification of montages. The following data were then recorded: area of lamina quantified, number of plaques within the lamina, and area of plaques within the lamina. Plaques were defined by the routine criteria employed since Alzheimer's time: namely, the presence of amyloid, degenerating neuronal processes, and neurofibrillary tangles (Terry and Katzman, 1983; Kemper, 1984). No attempt was made to discriminate so-called primitive, classical, and end-stage plaques (defined by greater and lesser degrees of amyloid and tangles), since the implied chronology and etiologic significance of these characterizations are still much disputed (Terry and Katzman, 1983; Kemper, 1984). Plaque concentration was defined as the number of plaques per square millimeter of cortex. Plaque areal concentration was defined as the area of plaques per square millimeter of cortex. Parts of plaques falling within and occupying more than half a grid square were scored as being part of the plaque. Discretely stained, isolated areas less than $400 \mu \mathrm{m}^{2}$ (one grid square) were found, on subsequent reference to the original sections, to be amyloid debris usually associated with small blood vessels, or cells filled with neurofibrillary tangles-more often the latter. Accordingly, this pathology was scored separately from plaque counts.

Statistics. The results of a three-way analysis of variance (patients $\times$ cortical region $x$ lamina) (Keppel, 1973) were virtually identical to those from a repeated measures two-way analysis of variance (cortical region $x$ lamina across patients) (Keppel, 1973). However, the repeated measures test did not given an estimate of differences within patients since each patient was measured only once at each cortical region and lamina; for this reason, the results described below are based on the three-way factorial analysis. The latter provides statistical tests for differences among patients, cortical regions, and cortical laminae, in addition to interactions between these factors (e.g., significant differences between cortical regions in the way plaques are distributed within their respective laminae).

\section{Results}

Plaque concentrations. The number of plaques per square millimeter of cortex differs significantly among laminae $\left(\mathrm{F}_{5.45}=11.93, p\right.$ $<0.0001$ ), with layers II, III, and IV having the highest concentrations $\left(\bar{X} \pm \mathrm{SEM}=60.8 \pm 7.6,51.4 \pm 6.1\right.$, and $59.5 \pm 13.4$ plaques $/ \mathrm{mm}^{2}$ respectively), and layers I and $V I$ having the lowest $(\bar{X}=31.3 \pm 5.3$ and $21.8 \pm 3.7$ plaques $/ \mathrm{mm}^{2}$, respectively). Plaque concentrations also differ significantly among patients $\left(F_{3,45}=19.34, p<0.001\right)$ and cortical regions $\left(F_{3,45}=5.15, p<0.005\right)$. Superior temporal (auditory) and striate visual cortex, both sensory areas, have more than $40 \%$ lower plaques concentrations than do superior frontal (Brodmann area 9) and anterior cingulate (Brodmann areas 23 and 24) gyri, classic association and limbic regions, respectively. Within patients, plaque concentrations range from a mean of $32.6 \pm 4.3$ to $68.2 \pm 10.3$ plaques $/ \mathrm{mm}^{2}$. These data indicate that the four Alzheimer's disease patient cases selected for study range from severe to extremely severe (Blessed et al., 1968). Although the regional and laminar patterns of plaque concentrations are highly similar within all patients (Fig. 2), they appear to be significantly accentuated in patients with more severe plaque pathology (as indicated by requisite inspection of the data after significant patient $\times$ lamina and patient $x$ cortical region interactions) $\left(F_{15,45}=4.07, \rho<0.001\right.$, and $F_{9.45}=$ $4.08, p<0.001$, respectively). Thus, as more and more cortical plaques are formed, they tend to occur with increasing frequency in layers II to IV and in association and limbic areas. The relative severity of our cases, and their attendant accentuation of laminar differences in pathology, may also explain why the paucity of plaques in laminae $\mathrm{I}$ and $\mathrm{V} \mid$-particularly the latter, where the relative laminar area is great and the number of plaques small-has not heretofore been reported. Indeed, in some sections from very severe cases, layer VI has, comparatively, so few plaques that the effect is visible without magnification (Fig. 3).

Plaque size. There are also highly significant regional $\left(F_{3,45}=\right.$ $4.60, p<0.01)$ and laminar $\left(F_{5,45}=10.91, p<0.001\right)$ differences in plaque size. Plaques are largest in laminae characterized by their preponderance of large pyramidal cells, layers III and $V(\bar{X}=2777$ $\pm 202 \mu \mathrm{m}^{2}$ and $\bar{X}=2502 \pm 123 \mu \mathrm{m}^{2}$, respectively); they are smallest in laminae with characteristically smaller, nonpyramidal cells, layers I and IV ( $\bar{X}=1535 \pm 139 \mu \mathrm{m}^{2}$ and $1602 \pm 74 \mu \mathrm{m}^{2}$, respectively) (Fig. 4). Plaque size does not differ significantly among patients. Since there is a significant range of severity among the patients (as judged by significant differences in plaque concentrations), these data suggest that plaques do not grow indefinitely but, instead, reach finite sizes predetermined by some cytologic characteristic of the lamina in which they occur.

Plaque areal concentration. The total area of plaques per square millimeter of cortex differs significantly among patients $\left(\mathrm{F}_{3,45}=22.88\right.$ $p<0.0001)$, cortical regions $\left(F_{3,45}=4.89, p<0.005\right)$, and laminae $\left(F_{5,45}=18.26, p<0.0001\right)$. Association and limbic areas again have higher values; primary sensory areas have lower values (Fig. 5) Likewise, plaque areal concentration is highest in layers II and III, and lowest in layers I and VI (Fig. 5). Layer N, which has large numbers of plaques, shows lesser values by measures of piaque areal concentration because the plaques found there, although numerous, are small. Inspection of the data for each patient suggests that the significant interaction of patients $\times$ lamina $\left(F_{15,45}=5.21, p\right.$ $<0.0001$ ) reflects an accentuation of the predilection of plaques for the upper cortical laminae in more severe patient cases.

\section{Discussion}

Quantitative assessments of plaque distributions and morphology reveal laminar and regional differences within neocortex. Although we note that difterential plaque distributions are most obvious in severe to very severe Alzheimer's disease cases such as those examined here, they can in fact be seen in the data of others. For example, Figure 4 in a report by Kosaka et al. (1984) shows, in schematic fashion, the location of plaques observed by the authors. Although they do not comment on the resulting pattern, it clearly matches the plaque distributions shown in Figures 2 to 4 of the present report, particularly with respect to the paucity of plaques in the infragranular laminae. Likewise, Mandybur (1975) states his qualitative impression that in temporal cortex, layers II, III, and V are most involved. These and other qualitative observations (Redlich, 1898; Fischer, 1907; Fuller, 1911; Tomlinson et al., 1968, 1970) are generally in agreement with our quantitative data.

Although early investigators typically regarded Alzheimer's disease as a primary cortical injury, it is now widely speculated that plaque etiology somehow cenlers on deterioration of extrinsic cortical afferent fibers, particularly those subcortical afferents having known neurotransmitter identity (e.g., cholinergic projections from the nucleus basalis of Meynert (nBM)) (Price et al., 1982; Struble et al., 1982; Coyle et al., 1983). However, our data suggest that plaque distributions correspond neither to specific thalamic input distributions (see below) nor to innervation patterns for any known neurotransmitter-specific subcortical afferent. This is particularly true for neocortical acetylcholine, presumably deriving from the $\mathrm{nBM}$. Insofar as it can be determined from the scant data on cholinesterase histochemistry (Mesulam et al., 1983) and immunocytochemistry (Hedreen et al., 1983), cholinergic projections are most dense in layer I and deep layer VI. These are precisely the laminae that have the fewest plaques (Fig. 4). Similar discrepancies exist for cortical noradrenergic projections (Morrison et al., 1982). With respect to hypotheses of plaques ctiology that focus on such subcortical nucle as the noradrenergic locus ceruleus (Bondareff et al., 1982; Iversen 


\section{A}

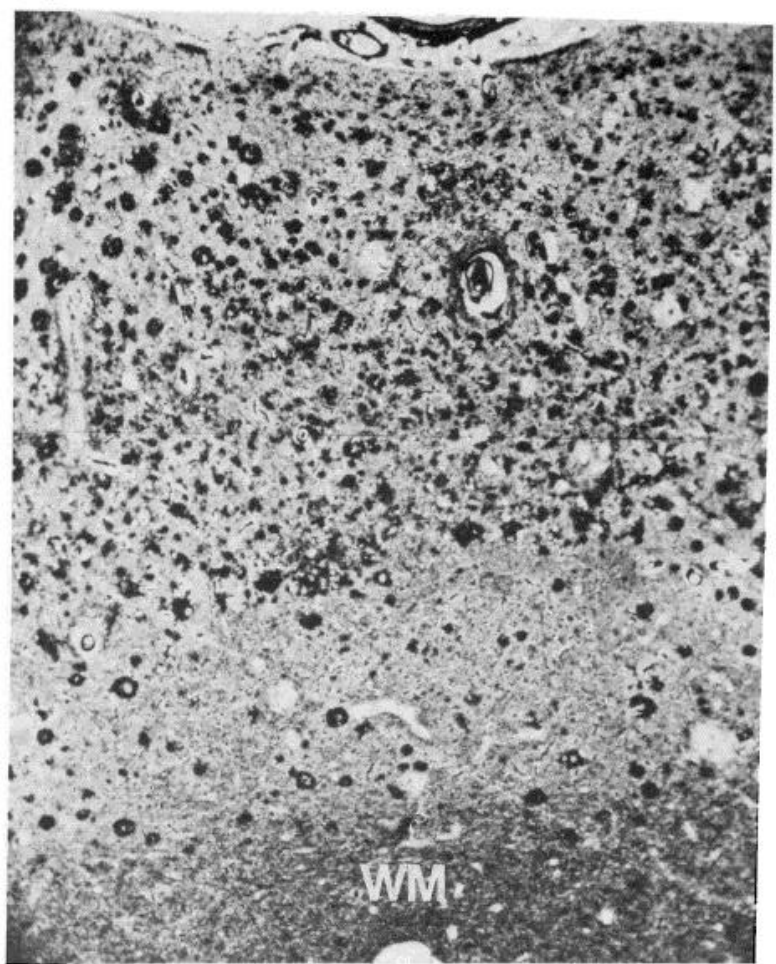

B

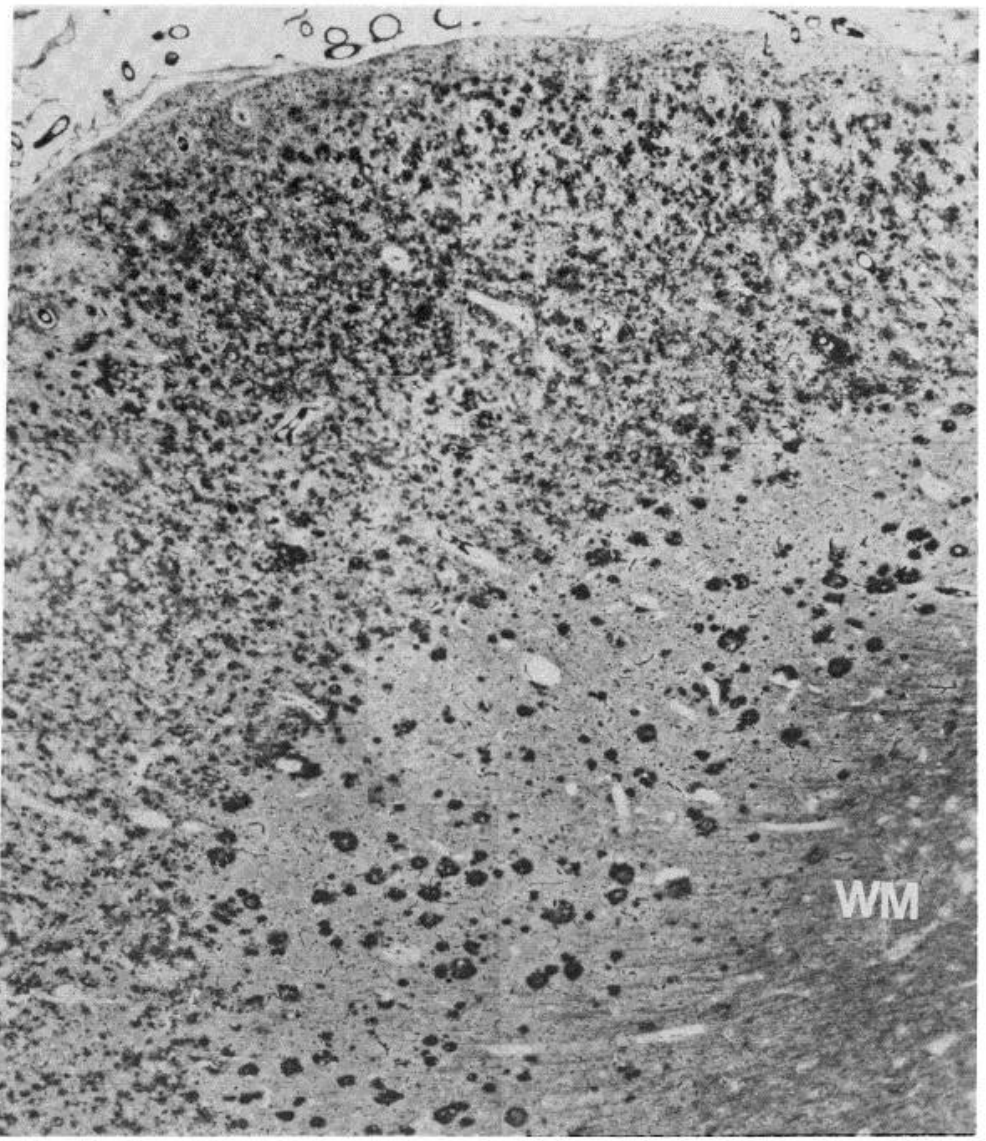

\section{C}
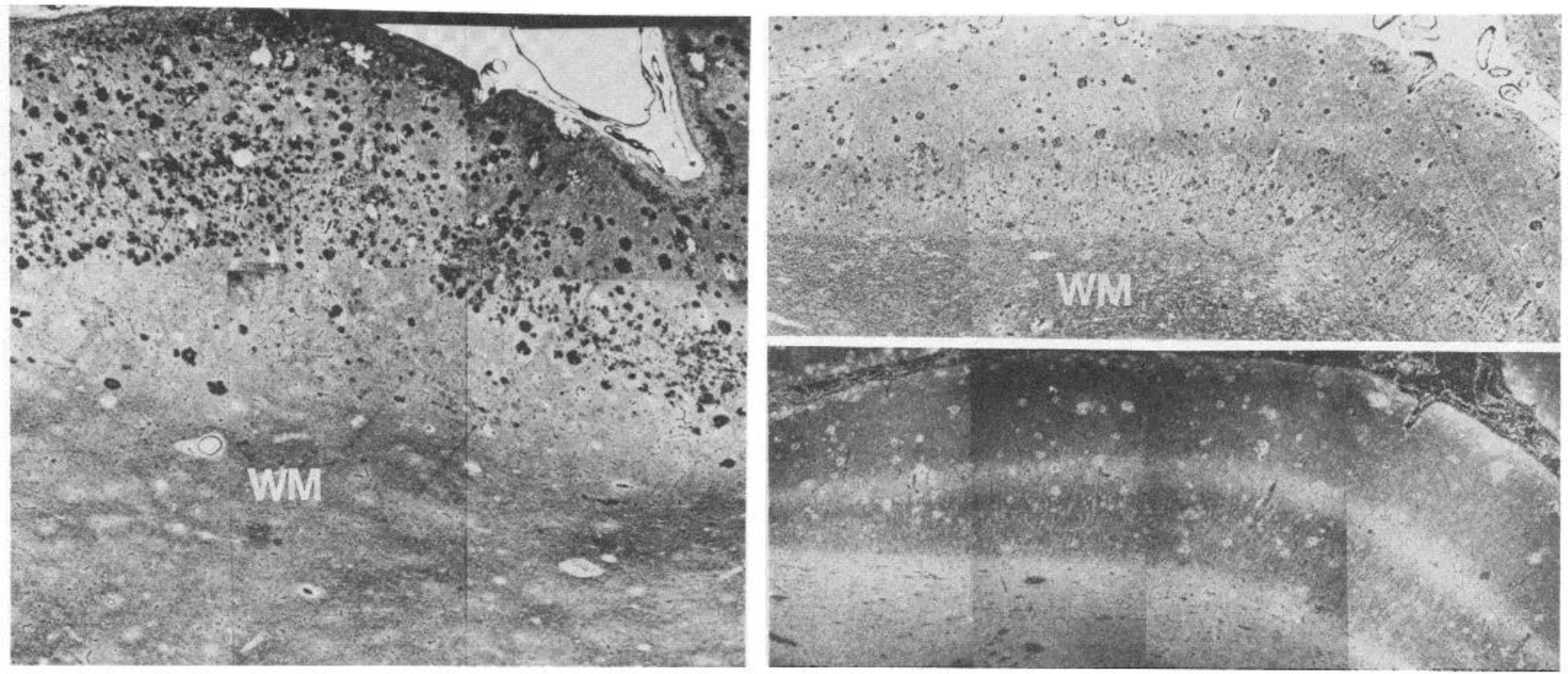

Figure 2. Typical photomontages of Bielschowsky staining from the four Alzheimer's disease patients and cortical regions. $A$, Superior frontal gyrus; $B$, anterior cingulate gyrus; $C$, superior temporal gyrus; $D$, striate visual cortex in bright (upper) and dark (lower) field. WM, white matter. 


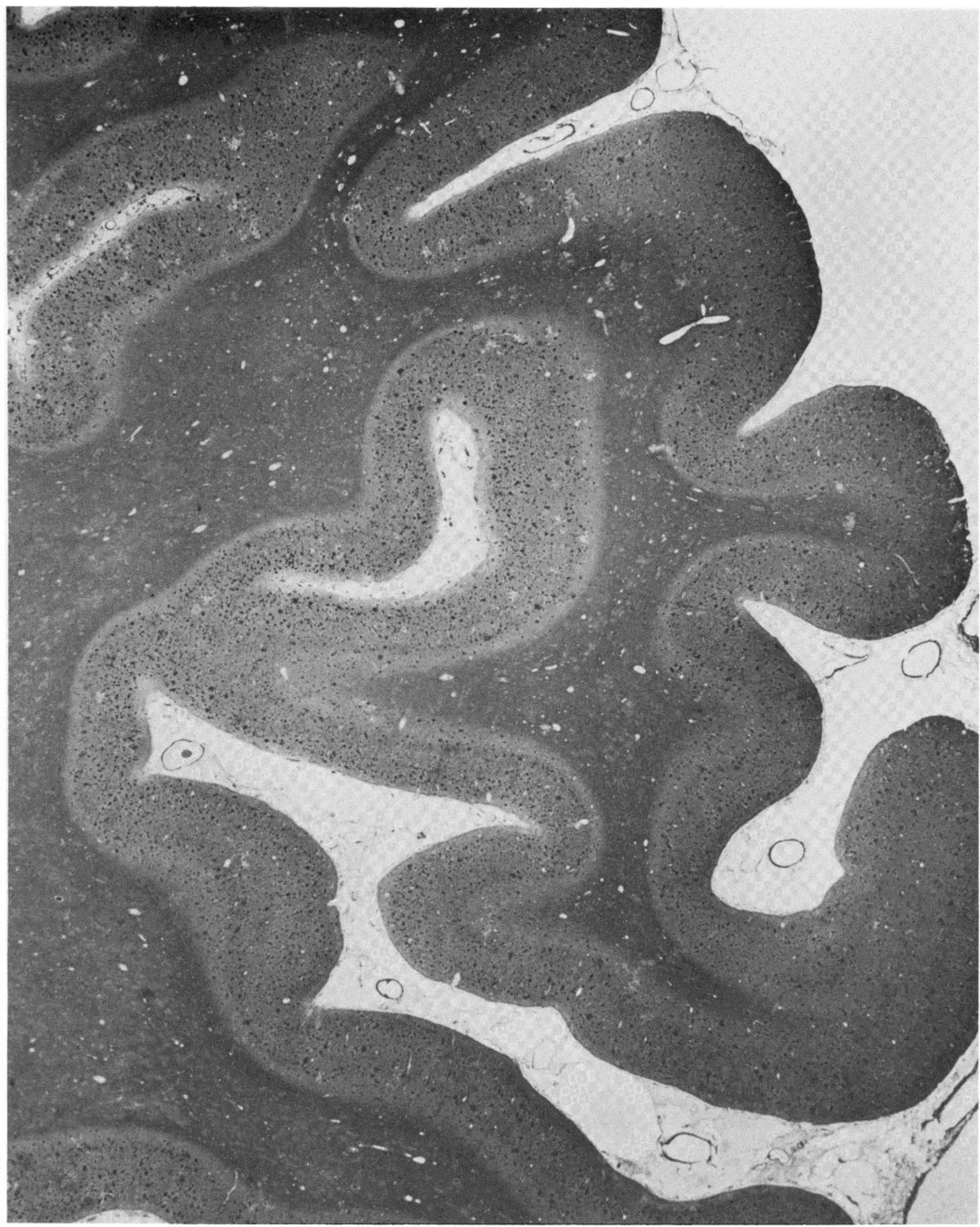

Figure 3. Photograph of a frontal lobe hemisection stained by the Bielschowsky method. There are comparatively so few plaques in layer VI that a distinct band is evident between the white matter and the more heavily stained layers superficial to layer VI. The paucity of layer I plaques is also evident in many areas. 
et al., 1983) or the cholinergic nBM (Price et al., 1982; Struble et al., 1982; Coyle et al., 1983), it is also difficult to reconcile the relative sparing of many brain regions in Alzheimer's disease (Mandybur, 1975; Jamada and Mehraein, 1977; Kemper, 1984) with the global reach of noradrenergic (Moore and Bloom, 1979; Morrison et al., 1982) and cholinergic (Mesulam and Van Hoesen, 1976; Mesulam et al., 1983) systems. The cerebellum, for example, receives a dense plexus of norepinephrine innervation (Bloom et al., 1972; Moore and Bloom, 1979) (in fact, locus ceruleus axons may bifurcate to reach both cerebellum and cortex through branches of the same axon) (Olson and Fuxe, 1971; Nakamura and Iwama, 1975; Nagai et al., 1981; Steindler, 1981), yet plaques in cerebellum are so scant as to be considered unusual (Kemper, 1984). Likewise, the nBM itself, one of the most densely cholinergic regions in brain (Mesulam et al., 1983), has few plaques (Jamada and Mehraein, 1977; Kemper, 1984). Co-localization of cholinesterase-positive fibers with plaques (Struble et al., 1982), along with other evidence (Price et al., 1982; Coyle et al., 1983), was once considered suggestive of a primary role in plaque etiology for cholinergic fibers presumably originating in the nBM. Since then, however, our work (Morrison et al., 1984, 1985) and that of others (Armstrong et al., 1984; Kitt et al., 1984) has shown that at least three other neurotransmitter-specific sets of fibers, somatostatin-, catecholamine-, and substance P-reactive neurites, can also be co-localized with plaques. This, at the least, casts grave doubts on the primary role of any single neurotransmitter system in plaque etiology and opens the strong possibility that virtually any or all cortical neurotransmitters may ultimately be found in one or another cortical plaque. In addition, previous emphasis on subcortical structures and their projections to cortex also appears

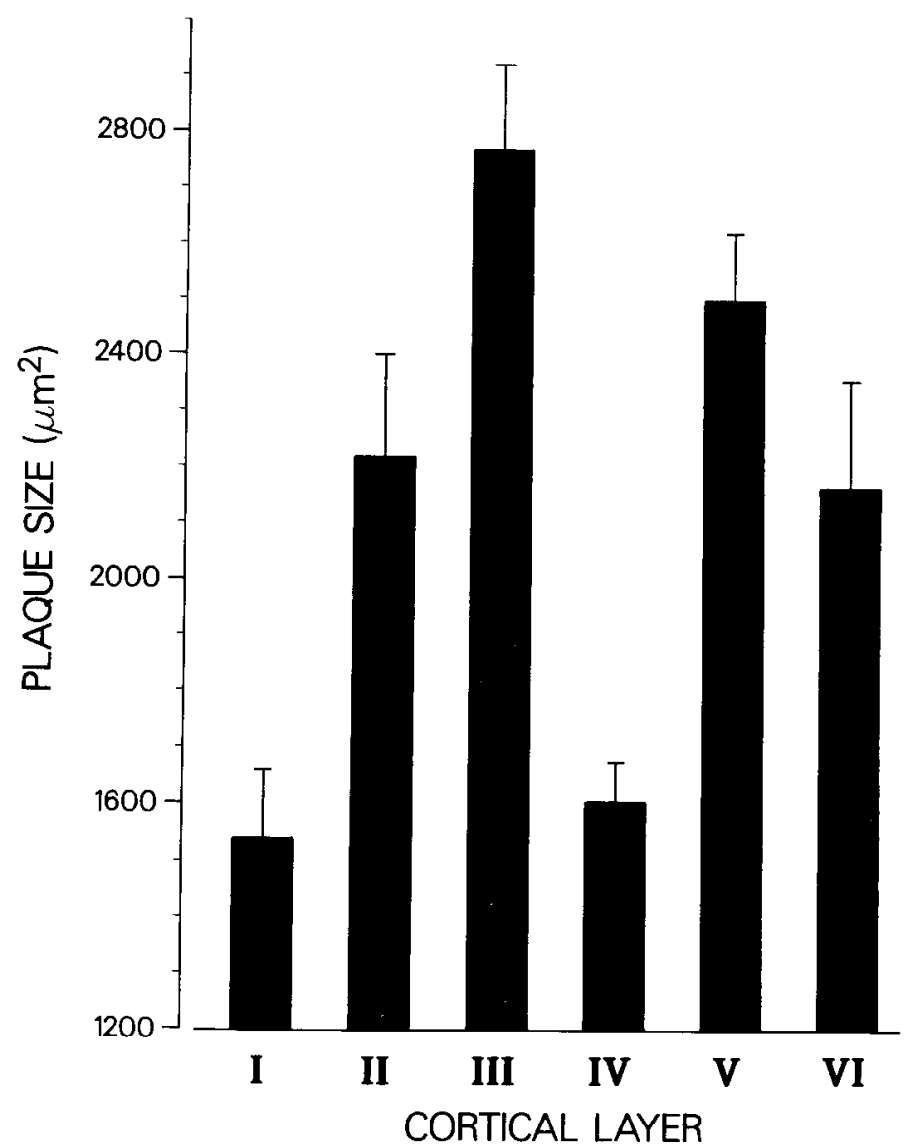

Figure 4. Mean cross-sectional area of neuritic plaques as a function of cortical lamina. Note that there is good corrcspondence between the size of cells typical of a lamina and the size of plaques found there. For example, plaques are largest in the pyramidal cell layers, III and V. Layers I and IV, dominated by neuropil and small cells, respeclively, have significantly smaller plaques.

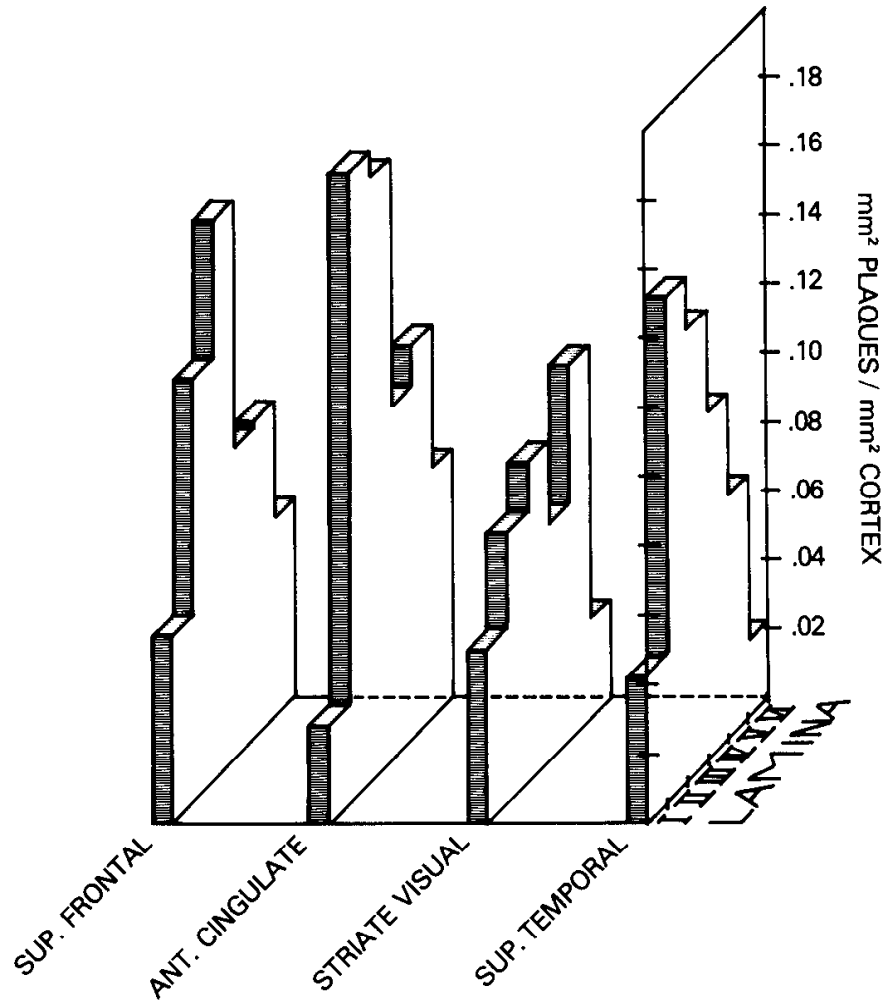

Figure 5. Plaque areal concentrations for layers I to $\mathrm{VI}$ across the four cortical regions studied. Note that the pattern of pathology, particularly the paucity of plaques in layers I and $\mathrm{VI}$, is consistent in all regions. Overall mean \pm SEM for these data is $0.091 \pm 0.007 \mathrm{~mm}^{2}$ of plaques $/ \mathrm{mm}^{2}$ of cortex.

less warranted given the somatostatin findings: cortical somatostatin most likely derives from a system intrinsic to cortex (Morrison et al., 1983; Hendry et al., 1984).

Although the large numbers of plaques in layer IV are consistent with specific thalamic input to cortex (Petcrs, 1979; Jones, 1981; Lund, 1981), several factors argue against a primary role for thalamocortical projections in Alzheimer's disease. Pathology of the thalamus itself does not appear prominent compared to other regions (Simma, 1951; Kemper, 1984). Moreover, a primary role for thalamic afferents, which terminate primarily in layer IV (Peters, 1979; Jones, 1981; Lund, 1981), does not account for equal or higher densities of plaques in layers II and III. Finally, thalamic involvement in plaque etiology is inconsistent with the paucity of layer VI plaques, since layer $\mathrm{Vl}$ is not only the recipient of a minor projection from the specific thalamic nuclei but is also the source of cortical projections to the thalamus (Lund, 1981; Jones, 1984)

If deterioration of subcortical afferents to cortex does not parsimoniously explain plaque distributions, what can? On the basis of our research, we suggest a nearly opposite hypothesis: the primary basis for neocortical plaque formation is the deterioration of neural elements intrinsic to the neocortex. Cortical plaque distributions and morphology are well correlated with several unique aspects of cortical cytoarchitecture, particularly those regions, laminae, and elements most involved in the functional integration of information from the various cortical regions (i.e., corticocortical association systems). For example, plaques are significantly more prevalent in superior frontal and anterior cingulate gyri, areas of extensive convergence of corticocortical systems, than in superior temporal and striate visual cortex, areas dominated by their connections with the thalamus. Furthermore, they are significantly more prevalent in layers that strongly participate in corticocortical connectivity, layers $\|$ and III, than in layers that do not, layers I and VI. It is possible, in fact, that layer IV plaques may also be related to degeneration of corticocortical systems, since in some regions layer IV receives signifi- 
cant corticocortical terminations, especially those characterized as feed-forward in an ascending hierarchical scheme (Van Essen and Maunsell, 1983).

Differences among laminae in the sizes of plaques are also parsimonious with an intrinsic cortical etiology. Plaques are largest in cortical laminae dominated by large pyramidal cells, source neurons for corticocortical relations (and cortical output in general); they are smallest in cortical laminae noteworthy for their small nonpyramidal cells, layers I and IV.

The idea of an intrinsic cortical origin for plaques may speak, albeit indirectly, to the problem of why several different neurotransmitters can be co-localized with plaques (Strublc ct al., 1982; Morrison et al., 1984, 1985; Armstrong et al., 1984; Kitt et al., 1984). Many different neurotransmitters impinge on cortical neurons and their neurites. If deterioration of these intrinsic cortical elements results in a plaque spread out over several thousand square micrometers, is it any great surprise that a particular neurotransmitter (or glial cell, artery, vessel, or capillary) normally contained in that region can subsequently be found there? The presence within plaques of dystrophic neurotransmitter-specific fibers, such as those we have previously demonstrated by somatostatin immunocytochemistry (Morrison et al., 1984, 1985), is stronger evidence for a causative role in plaque etiology than mere proximity to the plaque; but even here we note that the degeneration could equally well be due to loss of postsynaptic targets for afferent termination rather than the other way around. It may actually be the absence, rather than the colocalized presence, of certain elements that is significant

If one considers the basic principles of neocortical connectivity and begins to shift focus away from cholinergic and other subcortical afferent systems, a simple rationale presents itself for why plaques should take on a distribution pattern so clearly aligned with corticocortical association systems. There are two major afferent sources for any given area of the cortex. These are: (a) projections from other cortical areas and (b) projections from the thalamus. As proposed by Powell (1981), one or the other of these inputs appears to dominate in different cortical regions. At one extreme, for example, is the primary visual cortex (area 17), which is interconnected with relatively few other cortical regions (and only moderately interconnected even with these) (Van Essen and Maunsell, 1983), but which is extensively and reciprocally linked to its associated thalamic nucleus, the lateral geniculate nucleus (Gilbert and Wiesel, 1981). At the other extreme are such areas as the prefrontal association cortex. Here, corticocortical projections from diverse ipsilateral and contralateral cortical regions dominate, providing highly processed information from all sensory modalities (Jones and Powell, 1970). Thus, even if plaques were initially distributed randomly throughout neocortex, a cascade of pathology should occur in the association and limbic areas; for it is here that the most extensive convergence of corticocortical connections occurs. The association areas would then be expected to exhibit not only their own inherent pathology, but also an additional pathology deriving from deterioration of the multitude of other cortical regions projecting there. Our finding of an increased predilection of plaques for the association regions and laminae in increasingly severe Alzheimer's cases is consistent with such thinking. In this vicw, the dementia of Alzheimer's disease may reflect a neocortical isolation syndrome, wherein normal communications between the various neocortical regions are disrupted, and the associative functions so necessary to higher cognitive processes become tenuous. A similar explanation can be given for the pattern of Alzheimer's pathology recently described by Hyman et al. (1984) in hippocampus and entorhinal cortex. Our hypothesis predicts that there should be a cascade of pathology wherever there is a cascade of convergent cortical input, and this is precisely the effect Hyman et al. (1984) have so carefully documented in their description of hippocampal-entorhinal cortex input-output relations and the patterns of pathology found there. Thus, hippocampal isolation may be but one example of a widespread cortical phenomenon in Alzheimer's disease.

The degeneration of corticocortical association systems, as pro- posed here, would almost certainly exert a more profound effect on cognitive processing than would deterioration of cortical monaminergic or cholinergic innervation. Although pharmacologic blockade and/or lesions of the source nuclei for cortical monoamines and acetylcholine have been shown to impair memory (Bartus et al., 1982), the resulting deficits are difficult to describe as dementia

Future research is necessary to determine whether the possible role of intrinsic cortical elements in plaque formation is due primarily to pathology of cortical dendrites, axons, perikarya, or all of them combined. The classic ultrastructural studies of Terry et al. (1964, 1970) suggest that there are more dystrophic axons than dendrites in plaques, with cell bodies virtually absent. Our research also underscores the role of deteriorative axons in plaque pathogenesis. However, as opposed to previous reports (e.g., Price , 1982), our findings emphasize the powerful corticocortical association system rather than subcortical afferents to cortex.

\section{References}

Armstrong, D. M., D. Shields, and R. D. Terry (1984) Somatostatin- and substance P-like immunoreactivity within neuritic plaques. Soc. Neurosci. Abstr. 10: 271.

Bartus, R. T., R. L. Dean, B. Beer, and A. S. Lippa (1982) The cholinergic hypothesis of geriatric memory dysfunction. Science 217: 408-417.

Blessed, G., B. E. Tomlinson, and M. Roth (1968) The association between quantitative measurements of dementia and of senile changes in the cerebral gray matter of elderly subjects. Br. J. Psychiatry 114: 797-805.

Bloom, F. E., B. J. Hoffer, and G. R. Siggins (1972) Norepinephrine mediated cerebellar synapses: A model system for neuropsychopharmacology. Biol. Psychiatry 4: 157-177.

Bondareff, W., C. Q. Mountjoy, and M. Roth (1982) Loss of neurons of origin of the adrenergic projection to cerebral cortex (nucleus locus coeruleus) in senile dementia. Neurology 32: 164-168.

Braak, H. (1980) Studies of Brain Function. Vol. 4: Architectonics of the Human Telencephalic Cortex, Springer-Verlag, Berlin

Braak, H. (1984) Architectonics as seen by lipofuscin stains. In Cerebral Cortex. Vol. 1: Cellular Components of the Cerebral Cortex. A. A. Peters and E. G. Jones, eds., pp. 59-106, Plenum Press, New York.

Brockhaus, H. (1983) Zur anatomie des Mendelkerngebietes. J. Psychol. Neurol. 49: 1-36.

Coyle, J. T., D. L. Price, and M. R. DeLong (1983) Alzheimer's Disease: A disorder of cortical cholinergic innervation. Science 219: 1184-1190.

Feldman, M. L. (1984) Morphology of the neocortical pyramidal neuron. In Cerebral Cortex. Vol. 1: Cellular Components of the Cerebral Cortex, A A. Peters and E. G. Jones, eds., pp. 123-200, Plenum Press, New York.

Fischer, O. (1907) Miliare nekrosen mit drusigen wucherungen der neurofibrillen, eine regeimassige veranderung der hirnrinde bei seniler demenz. Monatsschr. Psychiatr. Neurol. 22: 361-372.

Fuller, S. C. (1911) A study of the miliary plaques found in brains of the aged. Am. J. Insanity 68: 147-219.

Gilbert, C. D., and T. N. Wiesel (1981) Laminar specialization and intracortical connections in cat primary visual cortex. In The Organization of the Cerebral Cortex, F. O. Schmitt, F. G. Worden, G. Adelman, and S. G. Dennis, eds., pp. 163-194, MIT Press, Cambridge, MA.

Hedreen, J. C., G. R. Uhl, S. J. Bacon, C. L. White, D. L. Price, and D. M. Fambrough (1983) A fiber network in monkey cerebral cortex revealed by acetylcholinesterase immunocytochemistry. Soc. Neurosci. Abstr. 9:212.

Hendry, H. C., E. G. Jones, and P. C. Emson (1984) Morphology, distribution, and synaptic relations of somatostatin- and neuropeptide $Y$-immunoreactive neurons in rat and monkey cortex. J. Neurosci. 4: 2497-2517.

Hooper, M. W., and F. S. Vogel (1976) The limbic system in Alzheimer's disease Am. J Pathol. 85: 1-13.

Hyman, B. T., G. W. Van Hoesen, A. R. Damasio, and C. L. Barnes (1984) Alzheimer's Disease: Cell-specific pathology isolates the hippocampal formation. Science 225: 1168-1170.

Iversen, L. L., M. N. Rossor, G. P. Reynolds, R. Hills, C. Q. Mountjoy, S. L. Foote, J. H. Morrison, and F. E. Bloom (1983) Neurosci. Lett. 39: 95-105. Jamada, M., and P. Mehraein (1968) Verteilungsmuster der senilen veranderungen im gehirn. Arch. Psychiatr. Neurol. 211: 308-324.

Jamada, M., and P. Mehraein (1977) Verteilungmuster der senilen veranderungen in den hirnstammkernen. Folia Psychiatr. Neurol Jpn. 31: 219-224.

Jones, E. G. (1981) Anatomy of cerebral cortex: Columnar input-output organization. In The Organization of the Cerebral Cortex, F. O. Schmitt, F. G. Worden, G. Adelman, and S. G. Dennis, eds., pp. 199-236, MIT Press, Cambridge, MA. 
Jones, E. G. (1984a) History of cortical cytology. In Cerebral Cortex, Vol. 1: Cellular Components of the Cerebral Cortex. A. A. Peters and E. G. Jones, eds., pp. 1-28, Plenum Press, New York.

Jones, E. G. (1984b) Laminar distribution of cortical efferent cells. In Cerebral Cortex. Vol. 1: Cellular Components of the Cerebral Cortex, A. A. Peters and E. G. Jones, eds., pp. 521-548, Plenum Press, New York.

Jones, E. G., and T. P. S. Powell (1970) An anatomical study of converging sensory pathways within the cerebral cortex of the monkey. Brain 93: 793-820.

Kemper, T. (1984) Neuroanatomical and neuropathological changes in normal aging and in dernentia. In Clinical Neurology of Aging, M. L. Albert, ed., pp. 9-52, Oxford University Press, New York.

Kemper, T. L., and A. M. Galaburda (1984) Principles of cytoarchitectonics. In Cerebral Cortex. Vol. 1: Cellular Components of the Cerebral Cortex, A. A. Peters and E. G. Jones, eds., pp. 35-54, Plenum Press, New York.

Keppel, G. (1973) Design and Analysis-A Researcher's Handbook, pp. 251-308, 423-456, Prentice-Hall, Inc., Englewood Cliffs, NJ.

Kitt, C. A., D. L. Price, R. G. Struble, L. C. Cork, L. C. Walker, W. C. Mobley, M. W. Becher, T. H. Joh, and B. H. Wainer (1984) Transmitter specificity of neurites in senile plaques of aged monkeys. Soc. Neurosci. Abstr. 10: 271.

Kosaka, K., M. Yoshimura, K. lkeda, and H. Budka (1984) Diffuse type of Lewy body disease: Progressive dementia with abundant cortical Lewy bodies and senile changes of varying degree-a new disease? Clin. Neuropathol. 3. 185-192.

Lund, J. S. (1973) Organization of neurons in the visual cortex, area 17, of the monkey (Macaca mulatta). J. Comp. Neurol. 147: 455-495.

Lund, J. S. (1981) Intrinsic organization of the primate visual cortex, area 17, as seen in Golgi preparations. In The Organization of the Cerebral Cortex, F. O. Schmitt, F. G. Worden, G. Adeiman, and S. G. Dennis, eds., pp. 105-124, MIT Press, Cambridge, MA.

Lund, J. S. (1984) Spiny stellate neurons. In Cerebral Cortex. Vol. 1: Cellular Components of the Cerebral Cortex, A. A. Peters and E. G. Jones, eds., pp. 255-308, Plenum Press, New York.

Mandybur, T. I. (1975) The incidence of cerebral amyloid angiopathy in Alzheimer's disease. Neurology 25: 120-126.

Mesulam, M. M., and G. W. Van Hoesen (1976) Acetylcholinesterase-rich projections from the basal forebrain of the rhesus monkey to neocortex. Brain Res. 109: 152-157.

Mesulam, M. M., E. J. Mufson, A. I. Levey, and B.H. Wainer (1983) Alzheimer's disease and the cholinergic innervation of neocortex by the nucleus basalis of Meynert (Ch4). In Banbury Report 15: Biological Aspects of Alzheimer's Disease, R. Katzman, ed., pp. 79-94, Cold Spring Harbor Laboratory, Cold Spring Harbor, NY.

Moore, R. Y., and F. E. Bloom (1979) Central catecholamine neuron systems: Anatomy and physiology of the norepinephrine and epinephrine systems. Annu. Rev. Neurosci. 2: 113-168.

Morrison, J. H., S. L. Foote, D. O'Conner, and F. E. Bloom (1982) Laminar, tangential and regional organization of the noradrenergic innervation of monkey cortex: Dopamine-B-hydroxylase immunohistochemistry. Brain Res. Bull. 9: 309-319.

Morrison, J. H., R. Benoit, P. J. Magistretti, and F. E. Bloom (1983) Immunohistochemical distribution of pro-somatostatin-related peptides in cerebral cortex. Brain Res. 262: 344-351.
Morrison, J. H., J. Rogers, S. Scherr, R. Benoit, and U. DeGirolami (1984) Neuropathology of the somatostatin system in neocortex of patients with senile dementia of the Alzheimer's type (SDAT). Soc. Neurosci. Abstr. 10: 894.

Morrison, J. H., J. Rogers, S. Scherr, R. Benoit, and F. E. Bloom (1985) Neuritic plaques of Alzheimer's patients contain somatostatin immunoreactivity. Nature 314: 90-92.

Nagai, T., K. Satoh, K. Imamoto, and T. Maeda (1981) Divergent projections of catecholamine neurons of the locus coeruleus as revealed by fluorescent retrograde double labeling technique. Neurosci. Lett. 23: 117-123.

Nakamura, S., and K. Iwama (1975) Antidromic activation of the rat locus coeruleus neurons from hippocampus, cerebral and cerebellar corticies. Brain Res. 99: 372-376.

Nieuwenhuys, R., J. Voogd, and Chr. van Huijzen (1981) The Human Central Nervous System, Springer-Verlag, Berlin.

Olson, L., and K. Fuxe (1971) On the projections from the locus coeruleus noradrenaline neurons: The cerebellar innervation. Brain Res. 28: 165171.

Peters, A. (1979) Thalamic input to the cerebral cortex. Trends Neurosci. 2: 183-185.

Price, D. L., P. J. Whitehouse, R. G. Struble, A. W. Clark, J. T. Coyle, M. R. DeLong, and J. C. Hedreen (1982) Basal forebrain cholinergic systems in Alzheimer's Disease and related dementias. Neurosci. Comment. 1: 8492.

Powell, T. P. S. (1981) Certain aspects of the intrinsic organisation of the cerebral cortex. In Brain Mechanisms and Perceptual Awareness, $\mathrm{O}$. Pompeiano and C. A. Marsan, eds., pp. 1-19, Raven Press, New York.

Redlich, E. (1898) Ueber miliare sklerose der hirnrinde bein seniler atrophie. Jahrbucher Psychiatr. Neurol. 17: 208-216.

Segerra, J. M. (1970) Histological and histochemical staining methods: A selection. In Neuropathology: Methods and Diagnosis, C. G. Tedeschi, ed., pp. 233-270, Little, Brown and Co., Boston.

Simma, K. (1951) Uber thalamusveranderıngen hei seniler demenz und be der Alzheimierschen krankheit. Monatsschr. Psychiatr. Neurol. 122: 156178.

Steindler, D. A. (1981) Locus coeruleus neurons have axons that branch to the forebrain and cerebellum. Brain Res. 223: 367-373.

Struble, R. G., L. C. Cork, P. J. Whitehouse, and D. L. Price (1982) Cholinergic innervation in neurilic plaques. Science 216: 413-415.

Terry, R. D., and R. Katzman (1983) Senile dementia of the Alzheimer's type: Defining a disease. In The Neurology of Aging, R. Katzman and R. D Terry, eds., pp. 51-84, F. A. Davis Co., New York.

Terry, R. D., and H. M. Wisniewski (1970) The ultrastructure of the neurofibrillary tangle and the senile plaque. In CIBA Foundation Symposium on Alzheimer's Disease and Related Conditions, G. E. W. Wolstenholme and M. O'Conner, eds., pp. 145-155, J \& A Churchill, London.

Terry, R. D., N. K. Gonatas, and M. Weiss (1964) Ultrastructural studies in Alzheimer's presenile dementia. Am. J. Pathol. 44: 269-283.

Tomlinson, B. E., G. Blessed, and M. Roth (1968) Observations on the brains of non-demented old people. J. Neurol. Sci. 7: 331- 356.

Tomlinson, B. E., G. Blessed, and M. Roth (1970) Observations on the brains of demented old people. J. Neurol. Sci. 11: 205-242.

Van Essen, D. C., and J. H. R. Maunsell (1983) Hierarchical organization and functional streams in the visual cortex. Trends Neurosci. $6: 370-375$. 